\title{
GERAKAN 5000 DONASI BUKU DALAM UPAYA MEMBANGUN BUDAYA LITERASI : TAHAP 2
}

\author{
Vidila Rosalina ${ }^{1}$, Donny Fernando ${ }^{2}$, Saefudin ${ }^{3}$, Hikmatullah ${ }^{4}$ \\ 1)Sistem Komputer, Universitas Serang Raya, ${ }^{23}$ Sistem Informasi Universitas Serang Raya, \\ 4)Pegiat Literasi, TBM Cilegon
}

${ }^{*}$ Corresponding Author, Emai: vidila.suhendarsah@gmail.com

\begin{abstract}
The society of a nation has a vertical relationship to the quality of the nation. The high interest in reading someone's book influences one's insight, mentality, and behavior. The Indonesian nation is a nation with a low literacy level even though it has been 70 years since Indonesia became an independent country. There are many factors why Indonesian society's literacy has a low percentage. These problems must immediately get serious attention not only from the government but from all of us. How does the discourse about "interest in reading " be carried out for all people when we still have a limited number of books read? So the book donation movement is in an effort to build a culture of literacy and literacy in Indonesia and in Banten in particular. When the state of literacy becomes a culture in Indonesia, it is not impossible that our nation will be an advanced nation.
\end{abstract}

Keywords: Banten, Literacy, Book Donation, interest in reading.

\begin{abstract}
Abstrak
Masyarakat suatu bangsa memiliki hubungan yang vertikal terhadap kualitas bangsa. Tingginya minat membaca buku seseorang berpengaruh terhadap wawasan, mental, dan prilaku seseorang. Bangsa Indonesia adalah bangsa dengan tingkat literasi yang masih rendah padahal sudah 70 tahun sejak Indonesia menjadi negara merdeka. Ada banyak faktor kenapa literasi masyarakat Indonesia memilki persentase yang rendah. Permasalahan ini harus segera mendapatkan perhatian serius bukan hanya dari pemerintah tapi dari kita semua. Bagaimana wacana mengenai minat baca menjadi terlaksana untuk semua kalangan masyarakat ketika kita masih memiliki keterbatasan jumlah buku yang dibaca?. Maka gerakan donasi 5000 buku tahap ke-2 ini adalah dalam upaya membangun budaya literasi dan semangat literasi di Indonesia dan di Banten khususnya. Ketika budaya literasi menjadi sebuah budaya di Indonesia maka bukanlah mustahil bangsa kita akan menjadi bangsa yang maju.
\end{abstract}

Kata Kunci: Banten, Budaya Literasi, Donasi Buku, Minat Baca.

Vidila Rosalina, Donny Fernando, Saefudin, Hikmatullah. Gerakan 5000 Donasi Buku Dalam Upaya Membangun Budaya Literasi : Tahap 2 


\section{Pendahuluan}

Potensi bangsa Indonesia sangat besar apabila ditinjau dari jumlah penduduknya yang terdiri dari berbagai suku, beraneka ragam budaya dan bahasa yang perlu dilestarikan keberadaannya. Namun, potensi yang sangat besar secara kuantitas itu perlu diimbangi dengan kualitas yang dimiliki. (Rosalina, 2017). Salah satu faktor penyebab Indonesia belum menempati posisi atas adalah karena rendahnya kualitas pendidikan (Rosalina, 2015). Keadaan tersebut diperburuk dengan masih dominannya budaya tutur daripada budaya baca. Somadayo dalam Triatma memaparkan bahwa "setiap aspek kehidupan melibatkan kegiatan membaca. Kenyataannya, minat membaca masyarakat khususnya anak sebagai pelajar saat ini masih rendah".Lebih lanjut Galus dalam Triatma memaparkan bahwa "rendahnya minat membaca masyarakat, erat hubungannya dengan tingkat pendidikan di negara tersebut". Sedangkan menurut peraturan UndangUndang Republik Indonesia Nomor 43 Tahun 2007 tentang Perpustakaan bahwa "budaya kegemaran membaca dilakukan melalui keluarga, satuan pendidikan, dan masyarakat dengan kerjasama antara pemerintah dalam upaya peningkatan minat baca, dimana pemerintah bertindak sebagai penanggungjawab utama dan pustakawan melakukan kinerja yang optimal".

$$
\text { Rahim dalam Triatma }
$$
menyebutkan bahwa "orang yang mempunyai minat baca yang kuat akan diwujudkannya dalam kesediaannya untuk mendapat bahan bacaan dan kemudian membacanya atas kesadarannya sendiri. Bahan bacaan yang dibaca meliputi surat kabar, majalah, buku pelajaran, buku pengetahuan di luar buku pelajaran, dan buku cerita". Timbulnya minat terhadap 
suatu objek ditandai dengan adanya rasa senang atau tertarik. Minat tidak hanya diekspresikan melalui pernyataan yang menunjukkan bahwa seseorang lebih menyukai sesuatu daripada yang lainnya, tapi juga dapat diimplementsikan melalui partisipasi aktif dalam suatu kegiatan.

Literasi dapat dipahami sebagai kemampuan kognitif untuk membaca dan menulis. Pengertian konsep literasi kemudian berkembang, yaitu dengan mengikutsertakan kemampuan berbicara secara lisan (oral) dan menghitung. Literasi adalah kemampuan hidup (life skill). Oleh karena itu, literasi merupakan kebutuhan hidup masyarakat maju. Tentu saja rendahnya literasi seseorang menghambat kemajuan suatu bangsa. Tingginya tingkat literasi seseorang akan menjadikan orang tersebut mampu melakukan fungsi-fungsinya di dalam kehidupan. Hal itu terlihat dari kemampuan seseorang dalam berbicara, memahami sebuah informasi dengan baik sehingga pada akhirnya mampu menyelesaikan masalah-masalah yang terjadi di dalam hidup. Dengan demikian berarti seseorang belajar mengembangkan potensi-potensi dalam dirinya untuk mencapai tujuan hidup.

Peran literasi sangat besar, semakin tinggi tingkat literasi seseorang maka akan semakin tinggi pula tingkat mutu wawasannya. Hal ini terlihat dari perbedaan masyarakat yang melek bacaan dan yang kurang bacaan. Jika dibandingkan masyarakat yang mengalami proses menyimak, membaca, menulis akan berbicara dan berpikir kritis juga tidak mudah termakan berita bohong (HOAX). Kehidupan yang bermutu tentu saja menjadi tujuan hidup setiap manusia. Untuk itu, kemampuan literasi sangat penting menjadi bekal diterimanya seseorang di dalam masyarakat itu sendiri. Tingginya tingkat literasi seseorang terlihat dari sejauh mana keluwesannya dalam berinteraksi dan bekerja sama di dalam lembaga-lembaga sosial yang ada di 
masyarakat. Hal ini sejalan dengan ungkapan (Magnessen dalam Silberman, 1996) bahwa "Kita belajar 10\% dari apa yang kita baca, 20\% dari apa yang kita dengar, 30\% dari apa yang kita lihat, 50\% dari apa yang kita lihat dan dengar, 70\% dari apa yang kita katakan, 90\% dari apa yang kita katakan dan lakukan." (Julianty, 2018).

Kemampuan literasi dalam hal ini dapat diartikan juga sebagai proses membaca. Membaca yang dimaksud adalah membaca dalam konteks yang sangat luas yaitu iqra'. Membaca untuk memahami, membaca untuk menganalisis lingkungan dan masalah sekitar untuk kemudian dapat digunakan sebagai bahan untuk memecahkan dan mencari solusi sebuah masalah kehidupan. Indeks minat baca di Indonesia baru mencapai 0,001. Artinya, pada setiap 1.000 orang, hanya ada satu orang yang punya minat membaca. Masyarakat di Indonesia ratarata membaca nol sampai satu buku per tahun. Kondisi ini lebih rendah dibandingkan penduduk di negaranegara anggota ASEAN, selain Indonesia, yang membaca dua sampai tiga buku dalam setahun. Angka tersebut kian timpang saat disandingkan dengan warga Amerika Serikat yang terbiasa membaca 10-20 buku per tahun. Saat bersamaan, warga Jepang membaca 10- 15 buku setahun. Tingkat literasi kita juga hanya berada pada rangking 64 dari 65 negara yang disurvei. Satu fakta lagi yang miris tingkat membaca siswa Indoneisa hanya menempat urutan 57 dari 65 negara (Republika, 12 September 2015).

Melihat kenyataan yang ada bahwa masyarakat Indonesia memiliki tingkat literasi yang masih rendah maka diperlukan sebuah perubahan. Perubahan di sini dapat kita mulai dari dimensi keluarga. Seperti dengan membangun budaya literasi di lingkungan keluarga yang ada di negeri ini. Misalnya dengan membiasakan anak-anak terampil membaca setiap harinya hingga membangun karakter 
peduli literasi dengan gerakan donasi buku bagi orang lain yang membutuhkan. Untuk melihat rendahnya minat membaca dengan mudah dapat dilihat dari daftar kunjungan masyarakat ke Perpustakaan atau ke Taman Bacaan Masyarakat (TBM). Minat baca masyarakat dengan memanfaatkan layanan perpustakaan di Banten masih rendah. Sebagai contoh di Dinas Perpustakaan dan Kearsipan (DPK) Kota Serang mencatat, sebanyak 23.337 pengunjung dari total tujuh

layanan perpustakaan yang disediakan sepanjang 2018. Kasi Layanan pada DPK Kota Serang Maryani mengatakan, dari tujuh layanan perpustakaan tersebut, dua di antaranya perpustakaan keliling (Pusling) di tempat mencatat 5.298 pengunjung dan layanan harian yang mencapai 5.839 pengunjung sepanjang 2018 (Kabar Banten, 2019).

Berikut ini adalah data responden dari 30 responden di wilayah Cilegon Banten yang dilakukan pada bulan Juli 2019:

Tabel 1.

Data Responden : Tingkat Minat Baca

\begin{tabular}{llc}
\hline No & \multicolumn{1}{c}{ Minat Baca } & Jumlah \\
\hline 1 & Tidak Pernah & 5 \\
\hline 2 & Kadang-kadang & 10 \\
\hline 3 & Pernah & 10 \\
\hline 4 & Sering & 5 \\
\hline
\end{tabular}

Dari tabel 1 di atas dapat dilihat memiliki minat baca yang cukup meskipun belum optimal

Tabel 2.

Data Responden : Tingkat Kunjungan ke TBM

\begin{tabular}{clc}
\hline No & Kunjungan ke TBM & Jumlah \\
\hline 1 & Tidak Pernah & 13 \\
\hline 2 & Kadang-kadang & 7 \\
\hline 3 & Pernah & 5 \\
\hline 4 & Sering & 5 \\
\hline
\end{tabular}

Vidila Rosalina, Donny Fernando, Saefudin, Hikmatullah. Gerakan 5000 Donasi Buku Dalam Upaya Membangun Budaya Literasi : Tahap 2 
Dan secara umum sebagian masyarakat pernah berkunjung ke TBM bahkan beberapa masyarakat menjadi pengunjung rutin, meskipun sebagian lain belum pernah karena tidak sempat atau belum mengetahui keberadaan TBM seperti yang terlihat pada tabel 2 .

Tabel 3.

\section{Data Responden : Tingkat Ketersediaan Buku di TBM}

\begin{tabular}{llc}
\hline No & Ketersediaan Buku & Tingkat \\
\hline 1 & Tidak Pernah & 18 \\
\hline 2 & Kadang-kadang & 7 \\
\hline 3 & Pernah & 3 \\
\hline 4 & Sering & 2 \\
\hline
\end{tabular}

Dari tabel 3 di atas dapat dilihat tingkat ketersediaan buku yang dicari oleh pengunjung masih rendah, hal ini disebabkan karena koleksi dan jumlah buku yang terbatas terutama buku-buku mata pelajaran SD, SMP, dan SMA .

Pengelola TBM di Cilegon, Banten umumnya memiliki beberapa kendala dalam meningkatkan minat baca masyarakat dan mengingkatkan jumlah pengunjung rutin TBM. Beberapa kendala yang dihadapi oleh pengelola TBM antara lain :

a. Masih terbatasnya kesediaan bukubuku di TBM.

b. Masih kurangnya pegiat literasi di masyarakat. c. Masyarakat belum memahami peran TBM sebagai salah satu penggerak kemajuan bangsa.

Kegiatan pengabdian masyarakat gerakan donasi buku dalam upaya membangun budaya literasi di Cilegon, Banten. Dari gerakan donasi buku ini diharapkan dapat memberikan manfaat dan tujuan sebagai berikut:

a. Menambah koleksi buku-buku di TBM sehingga menambah minat baca masyarakat

b. Menambah jumlah buku yang dibutuhkan di TBM untuk meningkatkan ketersediaan buku yang dibutuhkan masyarakat.

c. Menumbuhkan semangat literasi terutama bagi para pendonasi buku.

Vidila Rosalina, Donny Fernando, Saefudin, Hikmatullah. Gerakan 5000 Donasi Buku Dalam Upaya Membangun Budaya Literasi : Tahap 2 
Metode Pelaksanaan

\section{Metode Penyelesaian Masalah}

Untuk mengantisipasi permasalahan terbatasnya kesediaan buku di TBM Cilegon digunakan dua metode pendekatan seperti metode yang pernah dilakukan pada kegiatan pengabdian pada masyarakat sebelumnya yaitu Pengenalan Aplikasi e-CRM pada UMKM (Rosalina, 2017), yaitu:

Metode pertama, menggunakan metode pendekatan Kaji Tindak (Action Research) (Kleiman et al, 2001).Dalam kaji tindak partisipatif, kerja sama antara tim donasi dengan pemilik masalah (TBM) merupakan hal penting untuk diterapkan. Ketergantungan saling menguntungkan antara tim dan pemangku masalah terletak pada pemahaman bersama terhadap masalah yang harus dipecahkan, keterampilan, pengalaman, dan kompetensi; agar proses realisasi program dan pengembangannya dapat tercapai dengan optimal. Kaji tindak partisipatif merupakan kombinasi antara penelitian (research) dengan tindakan (action) yang dilakukan secara partisipatif guna meningkatkan aspek kehidupan masyarakat.

Metode kedua, adalah dengan metode peer coaching, yaitu suatu metode yang dilakukan untuk menyampaikan informasi, pesan, ide, pengetahuan yang dilakukan oleh teman sejawatnya. Dalam hal ini kami dosen Universitas Serang Raya menyampaikan gerakan donasi buku ini menggunakan sosial media dan dan menyebarkan melalui whatapp group (WAG).

\section{Tahapan Program Kegiatan}

Tahapan program yang dilakukan dalam kegiatan pengabdian masyarakat ini sebagai solusi permasalahan yang terjadi pada TBM Cilegon adalah:

a. Melakukan studi pendahuluan berupa kajian literatur terkait dan studi lapangan awal terkait literasi.

b. Melakukan survey dan observasi terhadap para minat baca masyarakat dan permasalahan TMB.

c. Melakukan tindakan pemecahan masalah keterbatasan koleksi dan jumlah buku di TBM dengan melakukan gerakan donasi buku. 


\section{Hasil Dan Pembahasan}

Buku adalah jendela dunia dan membaca adalah kuncinya. Kegiatan pengabdian gerakan donasi buku bertujuan meningkatkan minat membaca untuk menambah wawasan sekaligus mempengaruhi mental dan perilaku masyarakat. Pada gilirannya, kegemaran membaca ini akan membentuk budaya literasi yang berperan penting dalam menciptakan bangsa yang berkualitas. Rumusan ini mudah diucapkan, tetapi perlu kerja keras untuk diwujudkan, apalagi bila kita bicara tentang Indonesia, meski sudah 74 tahun merdeka, angka melek huruf kita masih rendah. UNDP merilis, angka melek huruf orang dewasa Indonesia hanya 65,5 persen. Sebagai perbandingan, angka melek huruf di negeri jiran, Malaysia, mencapai 86,4 persen. Hal ini terkait dengan pendidikan kita yang masih belum maju. Sebagai gambaran, berdasarkan data UNESCO, Indonesia berada di urutan ke-69 dari total 127 negara dalam indeks pembangunan pendidikan UNESCO.

Gerakan donasi buku dalam upaya meningkatkan budaya literasi tahap 1 dilakukan untuk di sumbangkan ke TBM Cilegon di Jalan Ciwedus - Gagunung Link.Curug Sekolah No.12 Bagundung Cilegon pada tanggal 5 -24 Juni 2020.

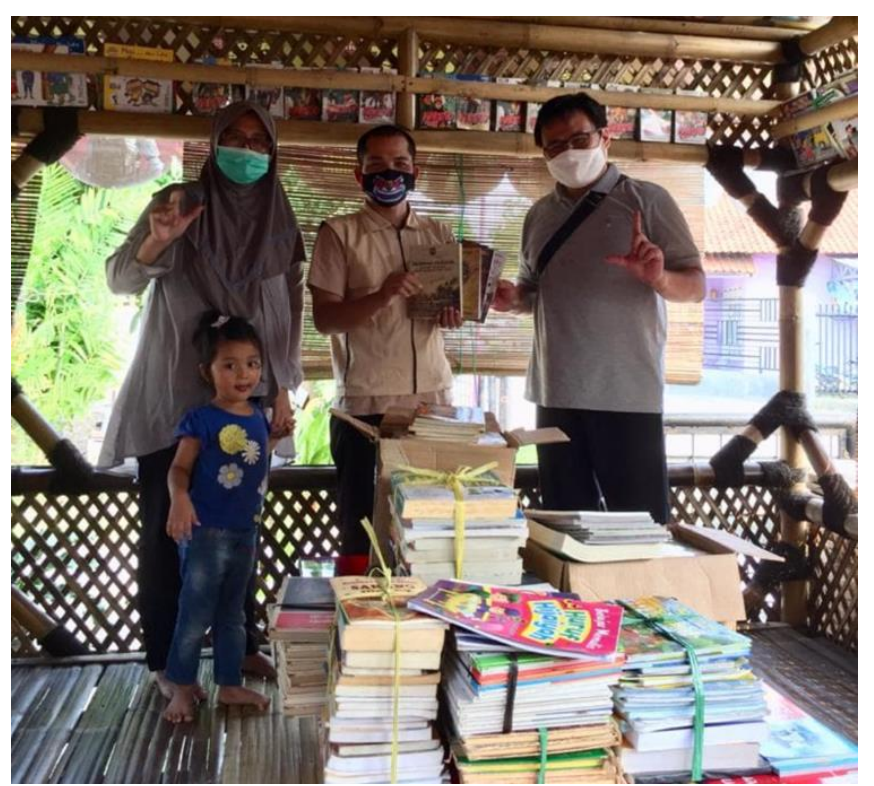

\section{Gambar 1.}

Forum Taman Bacaan Masyarakat (TBM) Cilegon

Vidila Rosalina, Donny Fernando, Saefudin, Hikmatullah. Gerakan 5000 Donasi Buku Dalam Upaya Membangun Budaya Literasi : Tahap 2 
Menambah donasi buku ditahap ke-1 sejumlah 214 buku, buku-buku yang telah disumbangkan pada tahap ke-2 ini sejumlah 200 buku dengan berbagai kriteria (tabel 4).

Tabel 4.

Daftar Donasi Buku

\begin{tabular}{llr}
\hline No & \multicolumn{1}{c}{ Kriteria Buku } & Jumlah \\
\hline 1 & Mata Pelajaran SD & 11 \\
\hline 2 & Mata Pelajaran SMP & 5 \\
\hline 3 & Mata Pelajaran SMA & 1 \\
\hline 4 & Kesehatan & 1 \\
\hline 5 & Novel & 10 \\
\hline 7 & Ensiklopedia & 48 \\
\hline 9 & Bahasa Arab & 1 \\
\hline 10 & TIK & 19 \\
\hline 11 & Komik & 61 \\
\hline 12 & Agama & 5 \\
\hline 13 & Bahasa Inggis & 11 \\
\hline 14 & Cerita Fiksi & 21 \\
\hline 15 & Majalah & 4 \\
\hline 16 & Budidaya & 1 \\
\hline 17 & TOEFL & 4 \\
\hline 18 & Jurnal Ilmiah & 1 \\
\hline & Total & $\mathbf{2 0 0}$ \\
\hline
\end{tabular}

\section{Simpulan}

Gerakan donasi buku ini adalah untuk meningkatkan jumlah koleksi dan jumlah ketersediaan buku di TBM Cilegon sehingga dapat meningkatkakan kunjungan masyarakat ke TBM dan meningkatkan minat masyarakat dalam upaya meningkatkan budaya literasi untuk masyarakat dan kemajuan bangsa Indonesia. Gerakan donasi buku tahap pertama ini diharapkan menjadi kegiatan pengabdian kepada masyarakat di Banten yang terus berkelanjutan.

Vidila Rosalina, Donny Fernando, Saefudin, Hikmatullah. Gerakan 5000 Donasi Buku Dalam Upaya Membangun Budaya Literasi : Tahap 2 


\section{Referensi}

Julianty, Ulfah. 2019. Membaca dan Gerakan Literasi Sekolah, DPK Provinsi Banten.

Peraturan Undang-Undang Republik Indonesia Nomor 43 Tahun 2007 tentang Perpustakaan.

Rosalina, Vidila, dkk. 2015. E-Pedagogis Bagi Tutor Untuk Meningkatkan Kualitas Pembelajaran Di Pusat Kegiatan Belajar Masyarakat (PKBM), Prosiding PKM-CSR 2015, Konferensi Nasional Pengabdian Kepada Masyarakat - Corporate Social Responsibility, 22-23 Oktober 2015.

Rosalina, Vidila, dkk. 2017. Model

Electronic Customer Relationship Management (E-CRM)

Menggunakan Adaptasi Bahasa

Lokal Pada Usaha Mikro Kecil Menengah (UMKM) Banten, Prosiding SENASSET 2017 (Seminar Nasional Riset Terapan) ISBN 978602-73672-0-3 : 12, November 2017.

Rosalina, Vidila, dkk. 2017. Sosialisasi Manfaat E-CRM dalam Upaya Meningkatkan Retensi Pelanggan
UMKM Cilegon. Jurnal Pengabdian Masyarakat Wikrama Parahita Vol 1 No 1, November 2017.

Rosalina, Vidila, dkk, 2019. Gerakan Donasi Buku Dalam Upaya Membangun Budaya Loiterasi Tahap 1. Seminar Hasil Pengabdian Kepada Masyarakat (SEMBADHA) PKNSTAN 2019.

Republika, 12 September 2015.

Wahyuni, Sri. 2009. Menumbuh kembangkan Minat Baca Menuju Masyarakat Literat, Universitas Islam Malang.

www.bantensatu.co.id/sukarela dan swadana forum TBM Cilegon konsisten gelorakan literasi, tanggal 17 Juli 2019,

www.kabar-banten.com/jumlahpengunjung-layanan-perpustakaanrendah/ (diakses pada tanggal 22 Juli 2019 Pk.15.50 wib).

www.Perpusnas.go.id (diakses pada tanggal 22 Juli 2019 Pk.16.00).

Vidila Rosalina, Donny Fernando, Saefudin, Hikmatullah. Gerakan 5000 Donasi Buku Dalam Upaya Membangun Budaya Literasi : Tahap 2 